1 A brief description of the provision of dental services in Australia with a particular emphasis on the treatment provided for patients at the dental centres of a private health fund

1 The role played by an independent certification body established to promote improvement in care standards is described

1 A program that has been devised by that body for healthcare providers to achieve accreditation as a provider of high quality care is described

1 The stages that were required to achieve the accreditation are described along with the inspection process

1 The value of the process for both staff and patients is discussed

\title{
The accreditation process of an Australian health fund's dental centre.
}

\author{
J. W. Toplis ${ }^{1}$
}

\author{
Accreditation by a recognised national quality control organisation is the ultimate accolade for any service provider. This \\ paper describes the processes and procedures that were undertaken by an Australian Health Fund's dental centres for \\ accreditation by the Australian Council on Healthcare Standards.
}

Dental treatment in Australia is normally provided under private contract between patient and provider. Medicare (the equivalent of the NHS) only provides limited treatment for 'safety net' groups.

The Federal government encourages membership of private health funds through financial incentives in the form of rebates on contributions, and also through penalties in the form of tax levies for higher income earners who do not belong to a fund.

One of the main differences between health funds in UK and Australia is that as well as covering claims for medical treatment, ancillary products can be purchased which provide cover for eye care and dental treatment. Depending upon the level of cover held, most routine dental treatment is covered, but a co-payment is required for high cost items such as crown and bridge work and orthodontics.

BACKGROUND OF THE DENTAL CENTRES The Australian Health Management Group has two dental and optical centres in New South Wales located in the city centre of Sydney, Parramatta (now the

1John W. Toplis, PO Box 1436, Parramatta, New South Wales 2124, Australia

\section{Refereed Paper}

Received 12.08.99; Accepted 27.10.99

๑ British Dental Journal 2002; 192: 71-73 geographic centre of Sydney) and a dental centre in Wagga Wagga, a city of about 50,000 in the south west of the state about $500 \mathrm{kms}$ from Sydney. Approximately 160 people are employed over the three centres; of this number there are 52 dentists, a lot of whom work part-time, splitting their working week between working for the fund, in general practice, specialist practice, hospital appointments, or post graduate education: eight have Fellowships, 11 have Masters degrees and there is one dentist with a PhD.

As well as dentists, there are also four hygienists, four prosthetists, four ceramicists and eight acrylic technicians.

Multi-skilling by dental nurses is actively encouraged and when they receive certificates of proficiency or qualify in the fields of dental radiography or oral health education, considerable salary enhancements are paid.

On the optical side there are four optometrists and three optical dispensers, and the optical consulting rooms are equipped with all the latest sight testing equipment along with diagnostic aids for the early detection of ocular diseases.

Other support staff include the computer service team who manage the extensive computer system that we have recently installed, linking all three centres and the fund's head office in Wollongong, a city 80 kilometres south of Sydney.
The computer system we have chosen is Dentrix, an American program, which is enabling us to become a 'paper less' operation, although it is fair to say that this has not been without considerable teething troubles.

Membership of the fund stands at about 110,000 plus dependents, and members of the health fund may access these centres for dental treatment and even with any co-payments that are required, treatment costs are much less than they would be in private practice. The centres are very modern and have state of the art equipment and we have always prided ourselves on the high standards that are employed, especially in the field of cross infection control methods. The sterilisation units are on a par with any hospital CSSD with a qualified technician in charge, and fully comply with all the latest sterilising standards.

A sedation unit was recently installed at the Parramatta centre which allows most oral surgery procedures to be performed 'in house', and the unit fully complies with all safety guidelines and is operated by staff who are fully accredited in conscious sedation.

In 1998, the Clinical Director of the fund, Dr David Buckley, decided that we should open our operation to the scrutiny of the Australian Council on Healthcare Standards (ACHS) to assess our standards as a provider of dental services for our 
members. No other organisation in this field had applied for accreditation and so we were breaking new ground.

\section{BACKGROUND ON THE ACHS AND EQUIP}

ACHS was founded in 1974 to encourage and assist healthcare organisations to continuously improve the quality of their services and provide a means for independent evaluation of those services. Over the years, programs evolved and 1996 saw the introduction of EQuIP - the Evaluation and Quality Improvement Program.

In this program, healthcare organisations were provided with a framework to deliver patient-focused services focusing on the continuum of care by incorporating systematic external peer review. The standards were developed and revised in cooperation with national healthcare organisations and cover all aspects of a service's operations that are integral in supporting the provision of care. They are applicable to hospitals, day procedure facilities, dental surgeries and many others in both the public and private sectors.

To be effective, EQuIP requires an integrated organisational approach to quality improvement by assisting healthcare organisations to:

- Improve overall performance

- Develop strong leadership

- Enjoy a culture of continuous quality improvement

- Focus on patients

- Focus on outcomes

EQuIP is both a training and assessment program. The standards that are addressed are considered essential elements in the provision of care, and are arranged into six functions. The greatest emphasis is placed upon:

- Continuum of care. This looks at how well the care given meets the needs and expectations of patients and the outcomes achieved. The continuum of care is supported by the functions of:

- Leadership and management

- Human resources

- Information management
- Safe practice and the environment and underpinning all of these functions is:

- Improving performance

The ACHS guides organisations through a period of self assessment using the EQuIP Quality Planning Workbook which allows comparison and continued review of performance against ACHS standards. A very comprehensive support service exist for guidance and counselling on issues of concern or recommendations made by the surveyors at the organisation wide survey, the culmination of the assessment process.

With all of this in mind, we embarked upon the process, guided and cajoled by Rhonda Mulligan in the Parramatta centre, and Edna Pineda in the Sydney city centre. Rhonda and Edna are both very experienced dental nurses and were selected for the positions after open competition within the dental centres.

Rhonda and Edna attended many courses and workshops and after many months of work submitted a pre survey report to the ACHS which lists the six areas previously described and how the required standards have been achieved. Not only did they have to prepare, train and educate the staff in the two Sydney centres, but they had to travel to and from the Wagga Wagga centre to do the same thing - a huge undertaking.

Groups of practitioners and dental nurses were organised to look into many aspects of our day to day operations. These included:

- An evaluation of treatment outcomes by peer review, mainly in the area of restorative dentistry with longevity and aesthetics of restorations analysed.

- A committee was established to oversee in-house Health and Safety issues.

- A committee was formed to organise a continuing education program.

- Peer audit of clinician record keeping standards was undertaken.

- A reassessment of some cross infection methods was undertaken which lead to a change in the hot air sterilising of orthodontic instruments as it was found to be a method which could not be calibrated accurately or documented.
- A re-evaluation of our Patient Satisfaction Surveys which are undertaken by the University of Adelaide.

- The introduction of courses for staff training using Stephen Covey's The Seven Habits of Highly Effective People.

A pre-survey document outlining what had been undertaken was submitted towards the end of 1998 and a date was set for the surveyors to visit over a 3-day period in March 1999. They spent a day in each centre. The survey was undertaken by trained personnel - industry peers who provide feedback on overall performance. At the moment, ACHS does not involve lay assessors, but this is an area which is currently being reassessed and in the future, one or more lay people may be involved in the survey process.

Our survey was conducted by a team of three - a dentist from an academic background at the University of Sydney Dental School, a cardiac unit manager from a private hospital and an ophthalmic surgeon.

All the pre-survey documentation was made available for inspection and was laid out to allow complete private access by the surveyors prior to presentations being made by staff members.

These presentations covered all six functions previously described as being the core of ACHS standards and were made by those who had been principally involved in evaluating our understanding of those specific areas.

The surveyors then had free access to all areas of the centres and were able to question staff members on aspects of their work including their understanding of evacuation procedures, emergency codes and procedures in use in the centres, and safe practice in the work place.

The purpose of the on-site survey is to verify the organisation's achievements in relation to ACHS standards and to prepare a summation of their findings, recommendations and guidance for future actions.

It is not just a 'one off' affair, but is repeated on a regular basis and, if standards are not maintained, the accreditation can be withdrawn at any time. 
Following its completion, a summary of the surveyors' findings is compiled to provide the organisation with:

- A detailed assessment of its performance against ACHS standards and criteria

- Identification of areas where performance is satisfactory or where further action is required

- Positive comments in areas of high achievement

- Suggestions for improvement.

After receiving the report, the organisation is required to draft a quality action plan that specifically addresses the surveyors' recommendations within a particular time frame. This becomes an agreement between the organisation and ACHS.

At the end of a very exhaustive 3 days, we were advised informally by the surveyors that we had more than satisfied the required standards in every single area and that only a few minor recommendations were to be made. Their report had to be submitted to the full ACHS board before we could be formally advised of our accreditation.

That was not the end of the process, as Rhonda and Edna had to submit an action plan to deal with the surveyors recommendations which again had to be approved by ACHS.

The accreditation will last for 3 years, the highest award that can be given, but can be revoked if a spot check reveals standards are not being maintained. We are aware that that has happened to some organisations and we are determined to ensure it does not happen to us.

Organisations that successfully achieve the ACHS standards are awarded a certificate of accreditation which is official acknowledgement of the commitment to continuous quality improvement.

A public relations kit is provided to assist the organisation to announce and publicise its achievement. This gives guidance on how the value and meaning of accreditation can be explained to patients in the context of the quality of care they receive and standards that are employed in the centres.

The fund publishes regular news letters for members along with an extensive web site, and a great deal of space was allocated in both areas following the accreditation. Feedback from members was very positive and we are quite sure that a good understanding of the significance of the accreditation was achieved.
The dental board of New South Wales would only permit members of the fund to be advised of the accreditation, but would not allow it to be generally advertised to the public.

\section{SUMMARY}

The first group of private dental centres in Australia to have received this accreditation, and the whole process was achieved through teamwork, a concept which is strongly held and nurtured throughout the whole of our health fund. It has given all the staff a feeling of recognition for the high standards that they routinely work to, and to know this has now been recognised by their peers. Our patients have also benefited from an improvement in the already high standards of care they receive. It has been a very positive process for all involved.

The author would like to thank Rhonda Mulligan and Edna Pineda, the EQuIP Coordinators, for their help during the preparation of this paper.

Further information about the Australian Council on Healthcare Standards can be obtained via the internet at www.achs.org.au and information about the Australian Health Management Group at www.ahmg.com.au 